\title{
DIVERSITY MANAGEMENT - PERCEPTIONS AND ATTITUDES BY CZECH MANAGERS
}

\section{Ludvík Eger, Zuzana Indruchová}

\section{Introduction}

The purpose of research survey is gaining basic information about the way managers in the Czech Republic perceive the significance of diversity management (DM). The survey is focused on a group of relevant respondents and the way they approach the implementation of diversity management in the field of the development of human resources in organizations in the Czech Republic.

The basis of diversity management concept can be seen in the natural substance of diversity existing in the human society where diversity of people from the point of their age, gender, race, ethnicity, mental and physical abilities, sexual orientation and other characteristics is a natural thing [3], [13], [11].

Diversity management, which originated in the US, came to Europe in the 1990s [13], [22] but in the EU company practice it has been developing and significantly applied only recently.

Hubbard [11, p. 27] defines diversity management as "a process of planning for, organizing, directing, and supporting these collective mixtures in a way that adds measurable difference to organizational performance." The concept of diversity management itself has been developing, for example, in the concept presented in Metcalfe and Woodhams [17], Holvino and Kamp [10], Eger et al. [3], Bleijenbergh et al. [1] or Kirton and Greene [14]. The latter two authors highlight the necessity of studying diversity management also from the point of view of the national specifics and the social context of any given country.

On the one hand, we can currently see the accent being put on more broadly interpreted approaches to diversity management linked with the concept of the organization culture but also linked with the social responsibility etc. On the other hand, we pay attention to the studies that highlight even specific features, for example Süß and Kleiner [22] for Germany, Risberg and Soderberg [19] for Denmark, Klarsfeld [15] for France or Kirton and Greene [14] for the UK.

In the Czech Republic diversity management has gradually become a topical and important issue in the field of the development and use of human resources, namely after the Czech Republic joined the European Union [4], [9].

\section{Research}

The purpose of the present research study is to describe the state of the factual perception of the diversity management issues in the organizations in the Czech Republic. The study is carried out by interviewing a relevant group of respondents.

\subsection{Research Questions and Objectives}

The basic research question is formulated as follows: "What is the current state of diversity management in companies in the Czech Republic?" It is obvious that our study can only be a partial output and has its limitations from the point of view of its focus and the set of respondents. Its advantage is that it surely belongs to the first research studies in the Czech Republic focusing on managers and HR specialists.

The research study implemented with the group of managers and HR specialists, especially from the companies situated in Prague has its objective in finding out about the existing state of the perception of the significance of diversity with a set of respondents from the chosen target group. The analysis of the output of the research will bring deeper knowledge of the 
monitored issues concerning the target group on an example of the respondents' set and subsequently topics for the field of further education in context of the development of diversity management in organizations in the Czech Republic. We are aware of the limitations resulting from the possibility of only partial research as far as the representativeness of the set is concerned, but the intention is to gain a number of respondents so that the outputs may enrich our knowledge in this field, be it only in a limited way. With regard to the novelty of the topic in the Czech Republic there have been no similar research studies or outputs of quantitative research of managers in the diversity field published as yet.

The specific research questions were formulated as follows:

- What is the existing state of the perception of the significance of diversity management by the group of managers and HR specialists in the organizations operating on the Czech market?

- How is diversity perceived as "a phenomenon of our times" by the group of managers?

\subsection{Methodology of the Research Survey}

For the planned research the method of interviewing was chosen and the tool was an electronic questionnaire as a way of asking questions and getting answers in writing. Its advantage consists in the possibility of contacting a large number of respondents in a short time.

The questionnaire was drawn up on the basis of research of the issues in the theoretical part.

Its structure and the content of the partial items are drawn up on the basis of foreign research studies. Owing to the fact that the sources of the selected fields are research studies focusing directly on diversity, equal opportunities or gender issues that had been carried out in the US and other countries in the past [7], [8], [11], [16], [18], it was necessary to modify them locally and to keep in the questionnaire only the fields applicable to the Czech environment.

The questionnaire (Diversity Management Survey = DMS) itself has been drawn up in such a way that in the items focusing on measuring the attitudes it uses the so called Likert scale which represents the most reliable techniques of measuring attitudes. The questionnaire consists of the statements with which a five point scale is used, from "Strongly agree" (point 1), through "Neither agree nor disagree", a medium scale point, up to "Strongly disagree" (point 5) representing the opposite end [20].

In our case the statements are structured in the individual sections of the questionnaire (dimensions of diversity management) and they are formulated unambiguously, which means that the size of the questionnaire is not big and any respondent only needs $15-20$ minutes to complete it. We consider this important because we know that managers in the Czech Republic are generally not willing to devote much of their time for such types of research even though these may be organized by an independent university.

The questionnaire DMS consisted of the following sections - dimensions of diversity management and their items:

- Managing people (3 items).

- Co-workers - Everyday interaction with colleagues at the same level (3 items).

- Principles of diversity management in personnel processes (3 items).

- Policies and procedures (4 items).

Three or four items measure each section dimension of diversity management.

The main part of the questionnaire was completed by one more complex item called: "Diversity as a phenomenon of our times", which was specified as follows: "I understand the concept of diversity management. I know the significance of diversity for the company where I work and I consider it important" (1 item). On the whole, there were 14 items.

Furthermore, the questionnaire also contained a specific section called "My own behaviour" (5 items), which focused on gaining information about the real behaviour of managers and HR specialists in the company practice.

The questionnaire was piloted on a sample of ten respondents - line managers - and its purpose was to verify whether the questions in the questionnaire were formulated properly, whether the respondents understand them and are willing to answer them. The stimuli from managers led to a partial alteration of some formulations as well as to the extension of the input information and to further specification of the time frame for the questionnaire completion. 


\subsection{Data Collection}

The respondents were sent an e-mail containing an active link to the questionnaire. Apart from the link to the questionnaire the respondents could also find in the above e-mail the information about the topic and length of the questionnaire as well as the reward for the respondents, consisting in the possibility of getting familiarised with the questionnaire results.

\section{The respondents}

Especially young workers in managerial positions or in the positions of a HR specialist with at least part time work responsibilities in the field of human resources management were the target group for the questionnaire survey. A non-random selection of respondents was chosen by means of the so called "snowball" technique and gradually 250 respondents were contacted from a number of companies operating in the Czech Republic, mainly from the Prague region (mostly international joint venture companies) and these were invited to participate in the research, either by means of e-mail or a social network (Facebook, Linkedln).

The return on the questionnaire answers was $39 \%$, the total of 98 respondents answered within two weeks. The average age of a respondent is 32 (the lowest age is 21 , the highest 53 , the most frequent age is $28 ; 29$ years of age is the median). Women account for $60 \%$ respondents. Most respondents are full time workers $(93 \%)$.

\section{Research Questions, Hypotheses and Partial Results}

For quantitative research the following partial research questions and hypotheses were formulated, and they are related to the desired target, i.e. the description of the perception of the significance - importance of diversity management in the workplace with a group of managers and other HR specialists. The significance of diversity management is constructed here on the basis of a summary (an average of the answers) that originated from the questionnaire outputs -4 sections and its items + additional aggregate items.

To test the below hypotheses a t-test for two independent selections was used and the processing was implemented by means of MS Excel. We aimed at looking for differences in the perception of diversity management with the monitored group of respondents from the point of their achieved level of education, the position in the organization, the size of the organization and the length of their work experience. For each individual area a question is asked and a hypothesis is set.

The decision whether there is a significant difference between the perception of diversity management with a group of the respondents according to the chosen viewpoint was taken on the basis of a t-test. Statistical tests were carried out at the 0.05 level of significance.

\section{Question No. 1:}

Does the level of achieved education of the respondents affect their perception of diversity management in the workplace?

\section{Hypothesis No. 1:}

$\mathrm{H}_{0}$ : There is no difference in the perception of the significance of diversity management with the group of respondents with a lower and higher level of education.

\section{Partial result}

- The set of respondents can be divided into the respondents with university education (4 graduates from Higher vocational schools are also included), where $n=78$, and the respondents with secondary school education, where $n=20$.

- The calculated value of the t-test is 0.939 and the level of significance is 1.984 . Because the calculated value is lower than the critical value we have to accept the null hypothesis. There is no statistically significant difference in the perception of diversity management on the basis of the applied aggregate data concerning the monitored groups of respondents according to their education (university, secondary).

Notice: there is problem with sample size; one sample is less than 30 participants [20]. Next results present two samples with similar size.

\section{Question No 2:}

Does the position of the respondents in the organization affect their perception of diversity management in the workplace?

\section{Hypothesis No. 2:}

$\mathrm{H}_{0}$ : There is no difference in the perception of the significance of diversity management depending on the position of the respondents in the organisations, i.e. managers or specialists. 


\section{Partial result}

- It is possible to divide the set of the respondents into two groups, i.e. the managers and managing directors $=$ the first group that manages other employees $(n=47)$ and the specialists whose responsibilities, at least partially, are the issues of the development of human resources in an organization, i.e. $\mathrm{n}=51$.

- The calculated value of the t-test is 0.040 and the level of significance is 1.984 . Because the calculated value is lower than the critical value we have to accept the null hypothesis. There is no statistically significant difference in the perception of diversity management on the basis of the applied aggregate data concerning the monitored groups of respondents - managers and respondents - specialists.

\section{Question No 3:}

Does the size of organization influence the perception of diversity management in the workplace by the interviewed respondents?

\section{Hypothesis No. 3}

$\mathrm{H}_{0}$ : With the monitored group of respondents there is no difference in the perception of the significance of diversity management in the workplace depending on the size of the organization in which they work.

\section{Partial result}

- Because experience with diversity management are especially in large enterprises the sample can be divided to a category of small and medium sized enterprises, i.e. up to 500 employees (55\%) and to a category of large enterprises - corporations, i.e. here 501 and more employees (45\% respondents). According to the definition of the US.

- The calculated value of the t-test is 0.202 and the level of significance is 1.984 . Because the calculated value is lower than the critical value we have to accept the null hypothesis. There is no statistically significant difference in the perception of diversity management on the basis of the applied aggregate data concerning the monitored groups of respondents depending on the size of organization.

\section{Question No 4:}

Does the work experience expressed in the number of years of the respondents affect the perception of diversity management in the workplace by the interviewed respondents?

\section{Hypothesis No. 4}

$\mathrm{H}_{0}$ : With the monitored group of respondents there is no difference in the perception of the significance of diversity management in the workplace depending on the length of their work experience.

\section{Partial result}

- The set of respondents can be divided into two groups; the first group includes workers with a short length of work experience of less than one year and 1-4 years of work experience, 43 respondents in total. The second group includes workers with the length of work experience of 5 and more years, i.e. 55 respondents.

- The calculated value of the t-test is 0.294 and the level of significance is 1.984 . Because the calculated value is lower than the critical value we have to accept the null hypothesis. There is no statistically significant difference in the perception of diversity management on the basis of the applied aggregate data concerning the monitored groups of respondents depending on the length of their work experience.

\subsection{Partial Conclusion Concerning the Research Survey}

We worked with a set of 98 respondents whom we divided according to their positions in organizations, their level of education, the size of the organization in which they work and also according to the length of their work experience.

With the monitored set of respondents we did not manage to prove any statistical significance of the difference in the perception of the significance of diversity management in the workplace depending on the above variables.

We have to highlight here that the sample is not representative and the results cannot be over generalised. Nevertheless, this reference survey, within the above mentioned monitored categories typical of the interviewed sample of respondents, represents a certain type of description of the perception of diversity management in the workplaces in the Czech Republic and this description corresponds with the general opinion that in the Czech Republic diversity management is still rather a new topic.

For that matter, the above state is illustrated even by a more detailed analysis of the special 
item "Diversity as a phenomenon of our times" which, in the questionnaire, is further specified by the statement: "I understand the concept of diversity management. I know the significance of diversity for the company where I work and I consider it important".

\section{Fig. 1: Responses concerning the item Diversity as a phenomenon of our times}

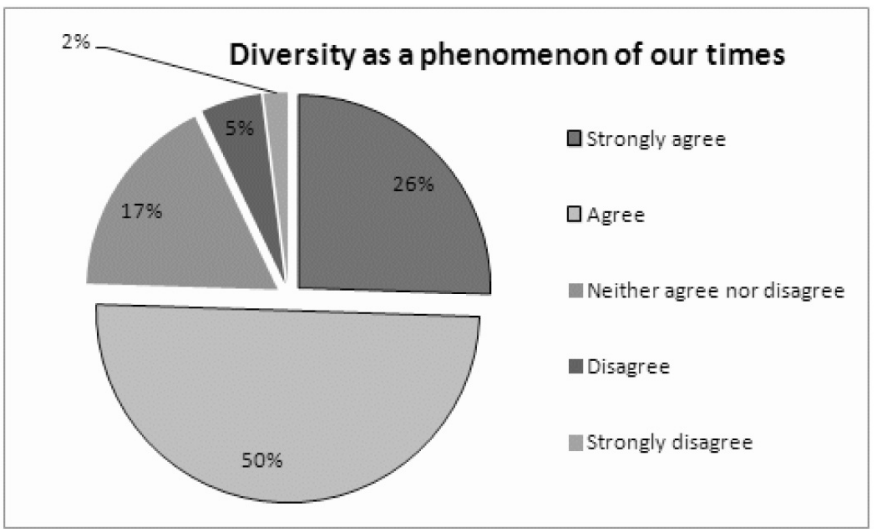

Source: own

A partial analysis of the answer Strongly agree showed that out of 25 answers - 14 respondents were from the category large enterprises (over 501 employees) and the analysis of the item Agree showed that out of 49 answers -20 respondents were from large enterprises - companies.

\section{The Assessment of the Research Tool and the Possibilities of Further Research}

As we have already stated, the present research study "The perceptions and attitudes of diversity in the workplace by managers in the Czech Republic" surely belongs to the first implemented research studies in the Czech Republic, where the issues of diversity management, both at academic and company level, belong to relatively new topics, see also Eger et al. [3].

Despite the limitations of the research resulting from the extent of the sample and the focus on the Prague region, it is possible to state some other interesting data which might be continued in any further research and which even today bring some important information about the perception of diversity management in the Czech Republic by company managers and HR specialists who, within their responsibilities, at least partly focus on managing human resources in organizations.

Here we would just like to remind that the questionnaire originated on the basis of inspiration from the research tools and outputs from the research studies presented abroad and before administering the questionnaire the tool was piloted in the Czech environment.

Completing the questionnaire enabled us to assess its basic qualities as a research tool. The validity may be adequately derived from the application of the given research tools. On the basis of piloting the questionnaire and its assessment by two experts we may say we consider the tool valid.

The reliability of the questionnaire was statistically assessed using Crombach's coefficient alpha for the individual parts of the questionnaire. Let us state the area, the number of items and the calculated result: Managing people (3 items), Crombach $\alpha=0.845$, Coworkers (3 items), Crombach $\alpha=0.632$, Principles of diversity management in personal processes (3 items), Crombach $\alpha=0.693$, Policies and procedures (4 items), Crombach $\alpha=0.772$.

Additionally even the following area was included in our research but we removed it from 
the complex output: My own behaviour (5 items), Crombach $\alpha=0.608$. This area was inspired by tools from the publication by Hubbard [11].

And, on the contrary, the item "diversity as a phenomenon of our times" was added to the above main items and is specified as follows: "I understand the concept of diversity management. I know the significance of diversity for the company where I work, and I consider it important" (1 item). This item belongs to the four specified areas as far as the content is concerned.

From the calculated Crombach $\alpha$ for the individual areas of the questionnaire it is obvious that two areas were given very good assessment. As far as possible further research is concerned we recommend considering the items in the area Co-workers and in the additional item My own behaviour. Here an opportunity for improving the applied research tool can be seen.

An additional view of the implemented research survey can be presented by calculating the correlations between the areas of the questionnaire and the gained aggregate index, with the interim name "significance of diversity management", fed from the above four sections of the questionnaire and the additional item.

Tab. 1: Pearson's coefficient of correlation, the individual sections - dimensions of DM

\begin{tabular}{l|c|c|c|c|c} 
& $\begin{array}{c}\text { Managing } \\
\text { people }\end{array}$ & Co-workers & $\begin{array}{c}\text { Principles } \\
\text { of DM }\end{array}$ & $\begin{array}{c}\text { Policies and } \\
\text { procedures }\end{array}$ & $\begin{array}{c}\text { Diversity as } \\
\text { a phenomenon } \\
\text { of our times }\end{array}$ \\
\hline Managing people & 1 & & & & \\
\hline Co-workers & 0.40 & 1 & & & \\
\hline Principles of DM & 0.27 & 0.47 & 1 & & \\
\hline Policies and procedures & 0.51 & 0.61 & 0.61 & 1 & \\
\hline $\begin{array}{l}\text { Diversity as a phenomenon } \\
\text { of our times }\end{array}$ & 0.70 & 0.71 & 0.74 & 0.92 & 1 \\
\hline Mean & 1.87 & 1.52 & 1.93 & 2.10 & 1.89 \\
\hline Standard deviation & 0.91 & 0.53 & 0.78 & 0.82 & 0.58 \\
\hline
\end{tabular}

Source: own

Table 1 summarizes our results and reports the correlation matrix along with sections' dimensions' means and standard deviations.

We can state that in our research survey a high level of correlation between the sections Politics and procedures and the overall index was achieved. The four sections - dimensions of DM correlated significantly with the overall index $=$ Diversity as a phenomenon of our times (14 items).

On the other hand, the additional section My own behaviour, fed from 5 items aimed at the assessment of the respondents' own behaviour in this field does not show a significant relationship to the overall index (significance of diversity management). This is certainly an important result even though it was only achieved with a limited set of respondents with an intentional selection by means of the snow-ball technique. It, in a way, illustrates the fact that the sample of respondents (managers and HR specialists with at least partial responsibilities in the $\mathrm{HR}$ management) is already aware of the concept of diversity management but their own behaviour still contradicts with this awareness of diversity management at a practical level (table 2).

We consider the above findings an interesting topic to be further used for personnel management and for adult education [2], [21]. To be an effective diversity manager, at a behavioural level, "you must be able to interact with others who are different from yourself". [11, p. 100]. An important finding of this survey is: there is contradiction and conflict between level of knowledge of DM and own behaviour of managers and HR specialists.

It is, however, necessary to support this phenomenon by further conclusions from practice; the best way to do it is further research. 


\begin{tabular}{l|c|c|c|c|c} 
& $\begin{array}{c}\text { Managing } \\
\text { people }\end{array}$ & Co-workers & $\begin{array}{c}\text { Principles of } \\
\text { DM }\end{array}$ & $\begin{array}{c}\text { Policies and } \\
\text { procedures }\end{array}$ & $\begin{array}{c}\text { Diversity as } \\
\text { a phenomenon } \\
\text { of our times }\end{array}$ \\
\hline My own behaviour & 0.05 & 0.14 & 0.04 & 0.15 & 0.14 \\
\hline
\end{tabular}

Source: own

\subsection{Research Limitations}

The validity of the research tool can be derived from its application as it was used in foreign research studies and from the expert assessment of the tool; the reliability of the applied tool can be supported by the Crombach $\alpha$ coefficient. What can be perceived as a limitation of the research is the small size of the group of the respondents from the capital of the Czech Republic, as this city is considered an important area of business and there are a number of joint venture companies. Therefore the results cannot be over generalized.

\section{Conclusion}

The research study implemented on a limited but relevant set of respondents did not prove any differences in the perception of diversity from the point of view of their achieved level of education, the position in the organization and the length of their work. On the whole, the index of the perception of diversity can be considered positive and it shows that the group of the relevant respondents is already familiar with the issue of diversity management. (Aggregately, the output was expressed as an average of the overall index for all the respondents by the value of 1.89 with a standard deviation 0.58 ).

The output from the present research study corresponds with a similar study carried out by Egerová et al [6] in which the above authors compared even the opinions of managers from the Czech Republic and the Slovak Republic (for Slovakia see also [12]).

Our desk research and quantitative research from the year 2012, aimed at the countries of the Visegrad Four [4], proves it necessary to pay attention even to the national and regional specifics when implementing diversity management in organizations, a fact also highlighted by Kirton and Greene [14] and other authors. On the other hand, it is also necessary to perceive common tendencies in the European Union that are typical of the field of diversity management, which are perceived, for example, by Wynne [23] as concentration on the following five groups: older workers, ethnic minorities representatives, representatives of some specific religions, women, and disabled workers.

A discovered contradiction between the perception of the significance of diversity management in an organization and the assessment of the behaviour of the monitored group by the respondents themselves may come as a sort of surprise. It may be necessary to focus on this issue in any further research but also in the process of implementing diversity management in practical operations of the Czech companies.

\section{References}

[1] BLEIJENBERGH, I., PETERS, P., POUSTMA, E. Diversity management beyond the business case. Equality, Diversity and Inclusion. 2010, Vol. 29, Iss. 5, pp. 413-421. ISSN 2040-7149.

[2] DE MEUSE, K., ENETH, P., HOSTAGER, T.J., CLAIRE, E., O'NEILL, K.S. A Longitudinal Evaluation of Senior Managers' Perceptions and Attitudes of a Workplace Diversity Training Program. HR. Human Resource Planning. 2007, Vol. 30, Iss. 2, pp. 38-46. ISSN 0199-8986.

[3] EGER, L. et al. Diverzity management. Praha: Educa service, 2009. ISBN 978-80-87306-03-1.

[4] EGER, L. et al. Diversity management. Comparison, the best practices of Visegrad countries. PIzeň: NAVA, 2012. ISBN 978-80-7211-420-7.

[5] EGEROVÁ, D. Diversity management as a crucial issue of the management in the $21^{\text {st }}$ century. Problems of management in the 21st century. 2012, Vol. 2, Iss. 3, pp. 5-7. ISSN 2029-6932.

[6] EGEROVÁ, D., JIŘINCOVÁ, M., LANČRIČ, D., SAVOV, R. Applying the concept of diversity management in organizations in the Czech Republic and the Slovak Republic - a research survey. Technological and Economic Development of Economy. 2013, Vol. 19, Iss. 2, pp. 350-366. ISSN 2029-4913. 


\section{Ekonomika a management}

[7] EEO TRUST. EEO Trust Diversity Survey Report 2005 [online]. Equal Employment Opportunities Trust, 2005. [cit. 2013-05-5]. 60 p. (PDF). Available from: http://www.eeotrust.org.nz/ content/docs/reports/Diversity\%20Survey\%20200 5\%20Report.pdf. ISSN 1176-8045.

[8] Ethnic Diversity Survey [online]. Statistics Canada, c2003 [cit. 2013-05-05]. Available from: http://www23.statcan.gc.ca/imdb/p2SV.pl?Function= getSurvey\&SDDS=4508\&ltem_ld=1717\&lang=en. [9] ELEXOVÁ, G. Human Resources Development under the Conditions of the Global Crisis. E+M Ekonomie a Management. 2011, Vol. 14, Iss. 3, pp. 46-55. ISSN 1212-3609.

[10] HOLVINO, E., KAMP, A. Diversity management: Are we moving in the right direction? Reflections from both sides of the North Atlantic Scandinavian. Journal of Management. 2009, Vol. 25, Iss. 4, pp. 395-403. ISSN 0956-5221.

[11] HUBBARD, E.E. Diversity management. Amherst: HRD Press, 2004. ISBN 0-87425-761-1. [12] CHEBEŇ, J., LANČARIČ, D., SAVOV, R., LOPES, P., BARBOSA, M. The perspectives of Diversity Management in Slovakia. Working Papers Fakulty mezinárodních vztahů. 2012, Vol. 5, Iss. 2, ISSN 1802-6583.

[13] IVANCEVICH, M.J., GILBERT, A.J. Diversity Management. Time for New Approach. Public Personnel Management. 2000, Vol. 25, Iss. 1, pp. 75-92. ISSN 0091-0260.

[14] KIRTON, G., GREENE, A-M. The Dynamics of Managing Diversity. A Critical Approach. Oxford: Butterworth-Heinemann, 2010. ISBN 9781-85617-812-9.

[15] KLARSFELD, A. The diffusion of diversity management: The case of France. Scandinavian Journal of Management. 2009, Vol. 25, Iss. 4, pp. 363-373. ISSN 0956-5221.

[16] MCCCD Diversity Survey [online]. Docstoc, 2010. [cit. 2013-05-05]. Available from: http://www.docstoc. com/docs/38713517/MCCCD-Diversity-Survey--Employee-Questionnaire-( $\mathrm{N}-=-1100)$.
[17] METCALFE, B.D., WOODHAMS, C. Critical perspectives in diversity and equality management. Gender in Management. 2008, Vol. 23, Iss. 6, pp. 377-380. ISSN 1754-2413.

[18] NESBITT, B. National Survey Reveals Diversity in the Workplace is Critical in Attracting and Retaining Talent [online]. Reuters, 2009 [cit. 2013-05-05]. Available from: http://www.reuters. com/article/2009/09/17/idUS94968+17-Sep2009+BW20090917.

[19] RISBERG, A., SODERBERG, A-M, Translating a management concept: diversity management in Denmark. Gender in Management. 2008, Vol. 23, Iss. 6, pp. 426-441. ISSN 1754-2413.

[20] SAUNDERS, M., LEWIS, P., THORNHILL, A. Research methods for business students. 5th ed. Harlow: Prentice Hall, 2009. ISBN 978-0-27371686-0.

[21] SEMRÁDOVÁ, I., KACETL, J. Ethics in the future manager's professional training. E+M Ekonomie a Management. 2011, Vol. 14, Iss. 2, pp. 79-89. ISSN 1212-3609.

[22] SUB, S., KLEINER, M. Dissemination of diversity management in Germany: A new institutionalist approach. European Management Journal. 2008, Vol. 26, Iss. 1, pp. 35-47. ISSN 0263-2373.

[23] WYNNE, R. Defining Diversity. BizEd. 2012, Vol. 11, Iss. 1, pp. 32-34. ISSN 1537-338X.

doc. PaedDr. Ludvík Eger, CSc. University of West Bohemia Faculty of Economics

Department of Marketing, Trade and Services leger@kmo.zcu.cz

Ing. Zuzana Indruchová Charles University in Prague Faculty of Arts

Department of Adult Education and Personnel Management zuzana.indruchova@gmail.com 


\section{DIVERSITY MANAGEMENT - PERCEPTIONS AND ATTITUDES BY CZECH MANAGERS}

\section{Ludvík Eger, Zuzana Indruchová}

Diversity management has become very important and relevant in the field of the human resource development namely after the Czech Republic joined the European Union. Diversity management is based on the strategy of an organization and it is also connected with corporate culture and corporate social responsibility.

The research focused on looking for the differences in the perception of diversity management of the monitored group of respondents from the point of view of their achieved level of education, the position in the organization, the organization size and the length of their work experience.

The respondents were young workers in managerial positions or in the positions of a HR specialist with at least part time work responsibilities in the field of human resources management.

The implemented t-tests did not prove any statistical significance in any of the monitored differences and it can be stated that with the monitored group there is no difference in the perception of diversity from the point of view of the level of their education, their positions in the organization, the organization size and the length of their work experience.

The complementary research by means of the Pearson's Correlation proved a positive relationship between the individual sections of the questionnaire and the overall perception of the significance of diversity management by the respondents and even a high level of correlation of the overall index with the section Policies and procedures. On the contrary, only weak values of correlation were achieved within the additional section focused at the respondents' own behaviour in their workplace in relation to the overall index of the perception of diversity management.

Key Words: Human capital, managers, organizations, diversity management, Czech Republic.

JEL Classification: M12, M53.

DOI: 10.15240/tul/001/2014-1-006 